\title{
Modified technique for double J stent removal
}

Técnica modificada para remoção de cateter duplo J

\section{Thiago Franchi Nunes ${ }^{1, a}$, Tiago Kojun Tibana ${ }^{1, b}$, Rômulo Florêncio Tristão Santos ${ }^{1, c}$, Riccardo Inchingolo ${ }^{2,3, d}$}

1. Hospital Universitário Maria Aparecida Pedrossian da Universidade Federal de Mato Grosso do Sul (HUMAP-UFMS), Campo Grande, MS, Brazil. 2. Interventional Radiology Unit, “F. Miulli” Regional General Hospital, Acquaviva dele Fonti (BA), Italy. 3. Radiology Department, King's College Hospital, London, UK.

Correspondence: Dr. Thiago Franchi Nunes. Avenida Senador Filinto Müller, 355, Vila Ipiranga. Campo Grande, MS, Brazil, 79080-190. Email: thiagofranchinunes@gmail.com.

a. https://orcid.org/0000-0003-0006-3725; b. https://orcid.org/0000-0001-5930-1383; c. https://orcid.org/0000-0002-8679-7369;

d. https://orcid.org/0000-0002-0253-5936.

Received 16 January 2020. Accepted after revision 4 May 2020.

How to cite this article:

Nunes TF, Tibana TK, Tristão Santos RF, Inchingolo R. Modified technique for double J stent removal. Radiol Bras. 2021 Mai/Jun;54(3):204-205.

\section{INTRODUCTION}

Interventional procedures have been used with increasing frequency for the diagnosis and treatment of urological disorders ${ }^{(1-5)}$. The classic method for removing double J (DJ) stents consists of a retrograde cystoscopic procedure involving the use of forceps ${ }^{(6-9)}$. However, retrograde removal may be difficult or not feasible in cases of DJ stent migration or abnormal ureter anatomy due to deviation or previous urinary tract surgery ${ }^{(10)}$. Some techniques to overcome these challenges have been described ${ }^{(7-11)}$. Kim et al. ${ }^{(12)}$ described a DJ stent removal technique using the combination of a snare and a guidewire.

The objective of this article is to describe a modified technique using only a combination of guidewires, replacing the use of a snare with that of a looped guidewire, together with a $9 \mathrm{~F}$ vascular introducer and a $5 \mathrm{~F}$ pigtail catheter, which could be equally effective and could reduce costs. Future studies with larger numbers of cases could compare these approaches in terms of their effectiveness and cost-benefit.

\section{PROCEDURE}

\section{Percutaneous transrenal removal}

Percutaneous access to the renal collecting system is typically achieved under ultrasound guidance with the patient in the lateral oblique position. Local anesthesia with $2 \%$ lidocaine $(10 \mathrm{~mL})$ is administered under conscious sedation. Transhepatic percutaneous puncture is then performed with a Chiba $17 \mathrm{G} \times 10.6 \mathrm{~cm}$ needle $(\mathrm{Ar}-$ gon Medical Devices, Frisco, TX, USA) and a 9F vascular introducer (Radifocus Introducer II; Terumo, Tokyo, Japan). Antegrade pyelography with injection of iodinated contrast is performed to visualize the anatomy of the collecting system and the position of the previously inserted DJ stent. A $5 \mathrm{~F} \times 90 \mathrm{~cm}$ pigtail catheter is then inserted into the renal pelvis. Through rotational maneuvers, the pigtail catheter is positioned to fully encompass the DJ stent (Figures 1A and 1B). Subsequently, a $0.035 " \times 180$ $\mathrm{cm}$ hydrophilic guidewire is passed through the pigtail, after which it is retracted in such a way that the circumferential wrapping of the DJ stent by the hydrophilic guidewire is maintained. A $0.014 " \times 300 \mathrm{~cm}$ guidewire is doubled and inserted in the form of a lasso. The hydrophilic guidewire is positioned inside the "lasso" formed by the 0.014" guidewire (Figures $1 \mathrm{C}$ and 1D). The 9F introducer is advanced to the captured segment of the DJ stent, which is then removed by the introducer together with the two guidewires. After the partial removal of the DJ stent through the external orifice of the introducer, the hydrophilic guidewire is again inserted up to its distal
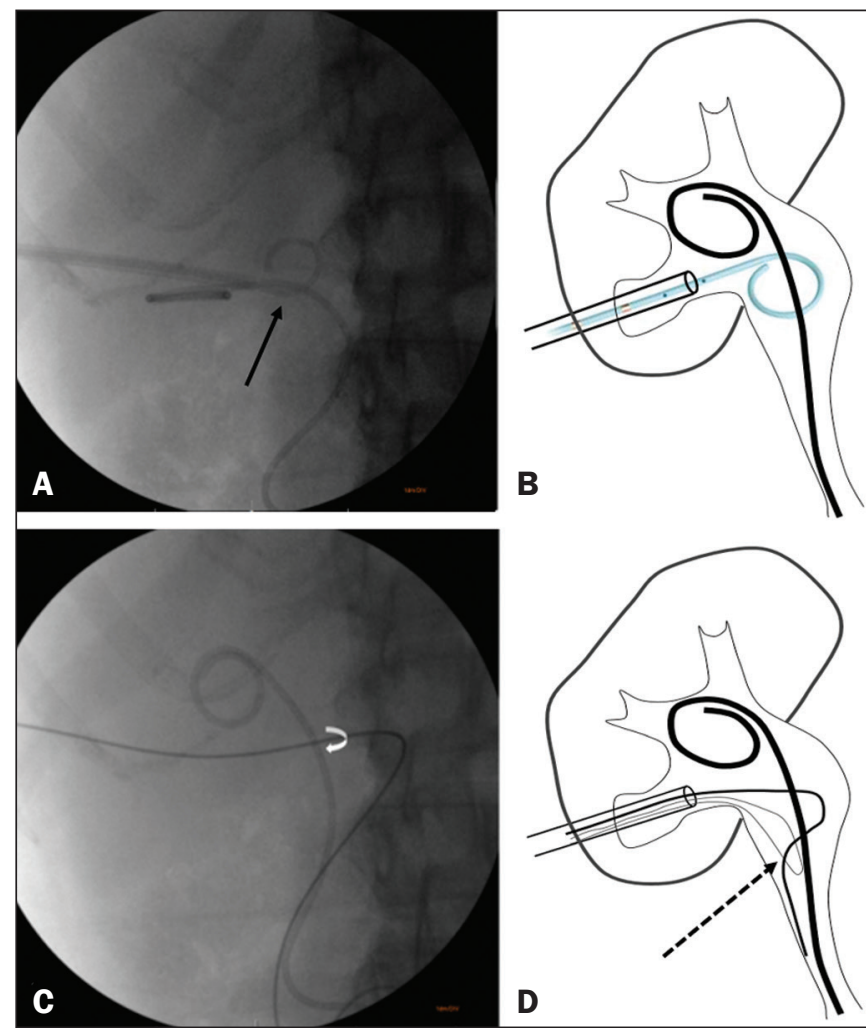

Figure 1. A,B: Passage of a $5 \mathrm{~F}$ pigtail catheter fully encompassing the DJ stent (arrow). C: Hydrophilic guidewire, after removal of the pigtail catheter, encompassing the DJ stent (curved arrow). D: Doubled 0.014" guidewire with the 0.035 " hydrophilic guidewire inside the loop (arrow). 
part. Finally, a new DJ stent is inserted by a technique previously described $^{(1)}$.

\section{Transurethral removal}

Transurethral access initially requires good asepsis of the vulvar region in women and of the penile region in men. Carefully and under fluoroscopy, a 9F valved introducer is passed into the bladder and then distended with approximately $200 \mathrm{~mL}$ of saline solution and $5 \%$ iodinated contrast, to ensure the safety of the procedure. Bladder anatomy and the position of the previously inserted DJ stent are evaluated under fluoroscopy. The same transrenal capture technique described above is performed. After the old DJ stent has been removed and the guidewire has been inserted into the renal pelvis, the new DJ stent is inserted. A bladder probe is left in place for the first $24 \mathrm{~h}$ to assess urine output and the functioning of the DJ stent.

\section{REFERENCES}

1. Nunes TF, Tibana TK, Santos RFT, et al. Percutaneous insertion of bilateral double J stent. Radiol Bras. 2019;52:104-5.

2. Meira MS, Barbosa PNVP, Bitencourt AGV, et al. Retrospective analysis of computed tomography-guided percutaneous nephrostomies in cancer patients. Radiol Bras. 2019;52:148-54.

3. Tibana TK, Grubert RM, Santos RFT, et al. Percutaneous nephrostomy versus antegrade double-J stent placement in the treatment of malignant obstructive uropathy: a cost-effectiveness analysis from the perspective of the Brazilian public health care system. Radiol Bras. 2019;52:305-11.

4. Tibana TK, Fornazari VAV, Gutierrez Junior W, et al. What the radiologist should know about the role of interventional radiology in urology. Radiol Bras. 2019;52:331-6.

5. Nunes TF, Tibana TK, Tristão Santos RF, et al. Percutaneous access for the diagnosis of urothelial neoplasms: pictorial essay with anatomopathological correlation. Radiol Bras. 2020;53:345-8.

6. Smith AD. Retrieval of ureteral stents. Urol Clin North Am. 1982; 9:109-12.

7. Patel U, Kellett MJ. The misplaced double J ureteric stent: technique for repositioning using the nitinol 'gooseneck' snare. Clin Radiol. 1994;49:333-6.

8. Naitoh J, Patel A, Fuchs GJ. A simplified method of ureteral stent removal using waterless rigid urethroscopy. J Urol. 1997;158:22256.

9. Uthappa MCCowan NC. Retrograde or antegrade double-pigtail stent placement for malignant ureteric obstruction? Clin Radiol. 2005;60:608-12.

10. LeRoy AJ, Williams HJ Jr, Segura JW, et al. Indwelling ureteral stents: percutaneous management of complications. Radiology. 1986;158:219-22.

11. Yeung EY, Carmody E, Thurston W, et al. Percutaneous fluoroscopically guided removal of dysfunctioning ureteral stents. Radiology. 1994;190:145-8.

12. Kim ET, Yang WJ, Shin JH, et al. Clinical utility of the modified snare technique for percutaneous antegrade removal of double $\mathrm{J}$ ureteral stents. J Vasc Interv Radiol. 2020;31:155-61. 